\title{
The study of carrying capacity of timber slabs with use the finite elements method
}

\author{
Vitalii Demeshok ${ }^{1 *}$, Alina Zalevs'ka ${ }^{1}$, Evgen Tychenko ${ }^{2}$ and Yana Zmaga ${ }^{1}$ \\ ${ }^{1}$ Cherkassy Institute of Fire Safety named after Chernobyl Heroes National University of Civil \\ Protection of Ukraine Science Department 18000 Cherkassy, Ukraine. \\ ${ }^{2}$ Educational-methodical Center of Civil Protection and Life Safety in Cherkasy Region, 18000 \\ Cherkassy, Ukraine.
}

\begin{abstract}
In the article, the results of the study of behavior of timber slab under influence of fire with the standard "time-temperature" curve are presented. The finite element method was used for it. For the calculation we constructed a grid models of timber slabs. As a result of solution of the thermal problem was obtained temperature distribution and the graphs of maximum deflection of timber slabs and its slew rate depending on the time of the test. The obtained graphs allow to obtain data on the occurrence of the limit state of loss of bearing capacity by comparing current values of displacements and velocities with the maximum allowable. Analysis of the graphs shows that the criteria limit state of loss of bearing capacity does not occur. Calculation method of evaluating the fire resistance of timber slabs was developed. For it use database about strain-stress state of this slabs in conditions of influence of the fire.
\end{abstract}

The construction of buildings, including multi-stored ones, with a large number of people in them often used wooden bearing structures. Such structures are made of timber slabs, but unless elements of wooden frames. The wood has a high strength, low specific weight and good decorative qualities. Wooden constructions provide durability of buildings and structures during exposure to fire. This must confirm with the requirements of the building regulations [1]. They are distributed for fire resistance and flame spread prevention. In the design of buildings these measures should be ensured through appropriate design solutions, incorporating the relevant safe geometric dimensions and measures of fire protection. At the stage of design of fire-resistant building structures calculated methods are used. Currently, theoretical and methodological framework of this approach is contained in the valid Ukrainian standard [2]. These methods are flexible and allow to consider all features related to the material properties, geometric dimensions and boundary conditions. However, they are much less labor-intensive and expensive for experimental methods.

Among the existing calculated methods, we can distinguish two types such us: simplified and clarified [3]. Simplified methods are simplified mathematical models. They are derived from a simple calculation formulas with the introduction of coefficients. Obtained during the synthesis of a large amount of experimental material. For development engineering calculation methods are applied refined methods. They are based on

\footnotetext{
*Corresponding author: scorpiomz@ukr.net
} 
mathematical modeling of the behavior of wooden structures in fire conditions at the macro level. For this methods the finite element methods in modern calculation of software complexes, such as ANSYS, Abaqus, SAFIR and others were involved [4, 5]. Taking into account it, the study was aimed at creating a reliable accurate mathematical models of the behavior of wooden structures in fire conditions is important.

\section{Analysis of recent achievements and publications}

In works $[4,5]$ an approach to study of the behavior of timber slabs during a fire, consisting in the carrying out mathematical modeling by the finite element method (hereinafter FEM) is offered. This approach refers to refined calculation methods and allows to describe accurately the behavior of timber slabs in fire. The obtained mathematical model in these works with the large volume of collected data have a significant disadvantage in the consideration of the deformation of timber slabs only in the elastic region. This situation is due to the fact that modern software systems should provide the difference of the elasticplastic properties of wood in tension and compression. There are still open questions of the distributions of the parameters of the tensely-deformed state (hereinafter - TDS) in crosssection, deformation scheme, distribution of defects, as well as information regarding the mechanism and causes of destruction of wooden floor slabs during a fire.

In this regard the purpose of the study is formulated.

\section{Formulation of the problem and its solution}

The objective of this work is to develop calculation methods for evaluating the fire resistance of timber slabs of ceiling on the basis of certain key parameters of the tenselydeformed state, charts of deformation, distribution of defects in the application of the finite elements method.

On fig. 1 chart of structural elements of wooden flag that is examined is given.

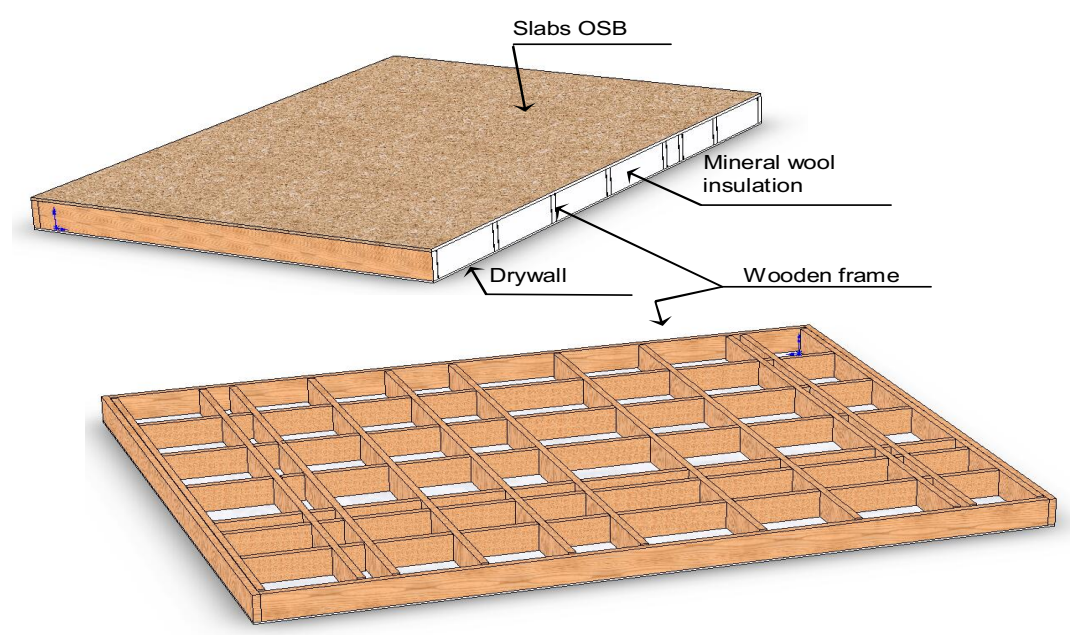

Fig. 1. Structural diagram of the wooden plate.

To solve this problem the formulation of set of input data is required, which include the properties of the components of the material wooden plate, parameters, boundary conditions, that take into account the applied loads and thermal effects. We used the thermal properties of the wood of the frame plates which are described in the European standard [3] concerning the calculation of wooden constructions for fire resistance. 
Used features meet the requirements of the European standard [3]. The mechanical characteristics are a set of diagrams "stress-strain" with the descending branches for certain values of the heating temperature of the material. For the calculation of it a mathematical model, whose parameters are given in tab. 1 was used.

Table 1. The basic mathematical models for calculation of the plate on fire.

\begin{tabular}{|l|l|c|}
\hline \multicolumn{1}{|c|}{ Physical process } & \multicolumn{1}{c|}{ Used mathematical model (method) } & J-lo \\
\hline Heating engineering task & \multicolumn{1}{|c|}{$\begin{array}{l}\text { Equalization of non-stationary heat-conducting, } \\
\text { approximated by means of FEM }\end{array}$} & {$[5]$} \\
\hline Heat-conducting & III kind & {$[5]$} \\
\hline Maximum terms & Iterative method Newton-Raphson & {$[5]$} \\
\hline Physical nonlinearity & FEM & {$[5]$} \\
\hline Static task & The associative theory of plastic deformation von Mises & {$[7]$} \\
\hline TDS & {$[7]$} \\
\hline $\begin{array}{l}\text { Plastic deformation } \\
\text { nonlinearity and geometric }\end{array}$ & Iterative method Newton-Raphson & {$\left[\begin{array}{l}|c| \\
\hline\end{array}\right.$}
\end{tabular}

For the boundary conditions was used the parameters of the European standard [3].

For the calculation we constructed a grid models of timber slabs are shown in Fig. 2. When constructing grid models for the heat task it was assumed 55,676 elements, and for static task, it was assumed 8142 elements.
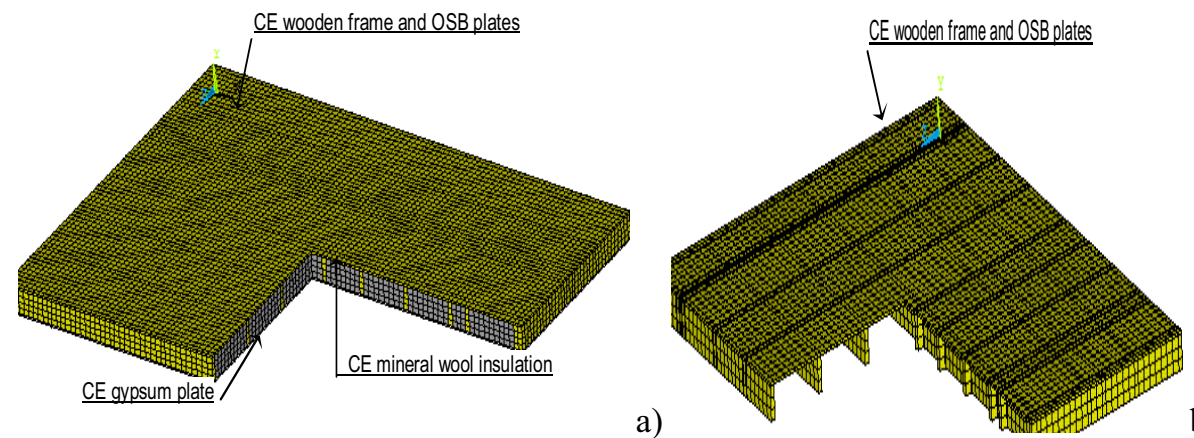

b)

Fig. 2. Grid models: the thermal problem (a); to the static task (b).

When we solved the statistical problem, we have received the graphs of maximum deflection of timber slabs and its slew rate depending on the time of the test. The obtained curves are shown in Fig. 3.

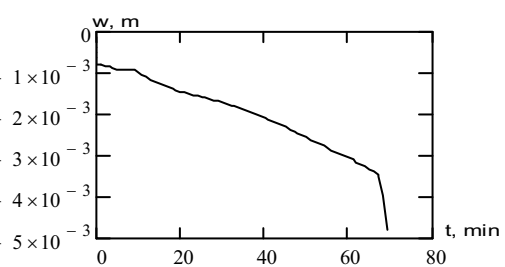

a)

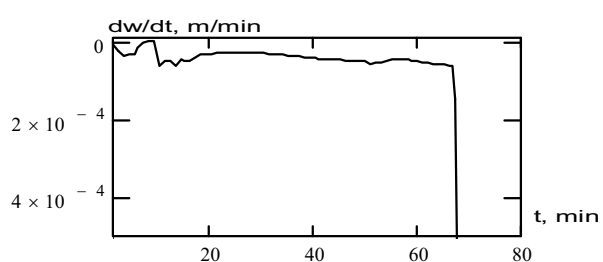

b)

Fig. 3. Graph of maximum deflection of a wooden plate (a) and slew rate (b) depending on the duration of the test.

The obtained graphs allow to obtain data on the occurrence of the limit state of loss of bearing capacity by comparing current values of displacements and velocities with the maximum allowable, which are respectively defined by the formulas [2]: 


$$
\begin{aligned}
& D=\frac{L^{2}}{400 \cdot b}=196.76 \mathrm{~mm} \\
& \frac{d D}{d t}=\frac{L^{2}}{9000 \cdot b}=8.79 \mathrm{~mm}
\end{aligned}
$$

where $L$ is the length of the plate between supports, mm, $b$ - height of cross section, $\mathrm{mm}$.

Analysis of the graphs shows that the criteria (1) limit state of loss of bearing capacity does not occur. Nevertheless, the abrupt increase of the deformations 68 min indicates the formation of plastic hinges in timber frame elements, which, in turn, shows the onset at the moment of loss of bearing capacity. Analysis of the graphs in Fig. 3 shows that the loss of bearing capacity occurs on the 68 minutes of fire with a standard temperature regime. This means that the fire resistance class of the investigated of timber slabs is not less than REI 60. The fire resistance class is the largest of the regulated [1].

Considering the conducted study we can draw the following conclusions:

1. Numerical study of the behavior of wooden plates during the operation of the fire with a standard temperature regime.

2. It was shown that wood slab at a certain time interval reduces its maximum deflection, then the value stabilized for nearly 40 minutes.

3. It was shown that the reduction of the maximum deflection of a wooden plate at a certain time interval, and further stabilization due to thermal expansion of the lower layers of the wooden beams of the slab.

4. It was revealed that the presence of gypsum plasterboard from below the ceiling allows to increase significantly the fire resistance of these boards due to loss of carrying capacity for fire resistance class REI 60.

5. The main provisions of the calculation methods of fire resistance assessment forr wooden slabs based on finite element method were developed.

\section{References}

1. DBN V.1.1-7-2002 Fire protection. Building structures fire safety, Kiev, (2003).

2. DSTU B V.1.1-4-98, Fire protection. Building structures. Fire resistance test methods. General requirements, ISO 834: 1975, Ukrarchbudinform, Kiev, (1998).

3. EN 1995-1-2:2004. Eurocode 5: Design of timber structures: General-Structural fire design Brussels (2004).

4. J. Konig L. Walleig Timber frame assemblies exposed to standard and parametric fires, Stocholm, (2000).

5. P.R. Collier, A. H. Buchanan, Fire Technology, 38, 125-145 (2002).

6. U. Franchuk Tables of thermal properties of building materials, (NII of building physics, 1972).

7. V. S. Sakharov Method finite element in solid mechanics (Higher school, 1982). 